\title{
Transcutaneous Oxygen Tension of Newborn Infants in Different Behavioral States
}

\author{
N. HANSON AND A. OKKEN ${ }^{(35)}$ \\ Department of Pediatrics, Division of Neonatology, University of Groningen, Groningen, The Netherlands
}

Summary

Transcutaneous oxygen tension (tcPO $\mathrm{O}_{2}$ ) was continuously monitored, and behavioral state was evaluated in a group of 10 normal preterm infants and 10 normal term infants. In the preterm infant group, birth weight was $1505 \pm 154 \mathrm{~g}$, gestational age was $32.3 \pm$ $2.3 \mathrm{wk}$, and postnatal age was $8.4 \pm 5.1$ days (mean \pm S.D.). In the term infant group, birth weight was $3245 \pm 247 \mathrm{~g}$, gestational age was $39.9 \pm 0.3 \mathrm{wk}$, and postnatal age was $6.3 \pm 3.4$ days (mean \pm S.D.).

A mean $\mathrm{tcPO}_{2}$ level for each behavioral state in each infant was calculated, and a paired comparison between all states was made. In the preterm and term infant groups, mean $\mathrm{tcPO}_{2}$ levels were higher in state 1 ("quiet sleep"), state 4 ("active awake state"), and state 5 ("crying") than during state 2 ("active sleep"). The difference $\left(\Delta \mathrm{tcPO}_{2}\right)$ was significant $(P<0.05)$. In the preterm infant group, mean tcPO ${ }_{2}$ level in state 2 was $62.9 \pm 17.1 \mathrm{~mm} \mathrm{Hg}$ (mean \pm S.D.). Mean $\Delta t c P_{2}$ in state 1 was $+5.4 \mathrm{~mm} \mathrm{Hg}$ (range, -0.9 to $+9.2 \mathrm{~mm} \mathrm{Hg}$ ), mean $\triangle \mathrm{tcPO}_{2}$ in state 4 was $+6.8 \mathrm{~mm} \mathrm{Hg}$ (range, +0.6 to $+20.2 \mathrm{~mm} \mathbf{~ g g}$ ), and in state 5 was $+9.9 \mathrm{~mm} \mathbf{~ g g}$ (range, +5.1 to $+17.5 \mathrm{~mm} \mathbf{H g}$ ). In the term infant group, mean tcPO ${ }_{2}$ level in state 2 was $64.5 \pm 9.6 \mathrm{~mm} \mathrm{Hg}$ (mean \pm S.D.). Mean $\Delta$ tcPO $_{2}$ in state 1 was $+5.8 \mathrm{~mm} \mathrm{Hg}$ (range, -1.2 to $+11.0 \mathrm{~mm}$ $\mathrm{Hg}$ ), mean $\Delta \mathrm{tcPO}_{2}$ in state 4 was $+8.1 \mathrm{~mm} \mathrm{Hg}$ (range, +2.2 to $+32.3 \mathrm{~mm} \mathrm{Hg}$ ), and mean $\triangle \mathrm{tcPO}_{2}$ in state 5 was $+7.3 \mathrm{~mm} \mathrm{Hg}$ (range, -1.6 to $+26.5 \mathrm{~mm} \mathrm{Hg}$ ). There was insufificient data to evaluate tc $\mathrm{PO}_{2}$ levels during state 3 ("quiet awake state"). In the term infant group, the effect of bottle feeding on tc $\mathrm{PO}_{2}$ was also assessed. Gross alterations in $\mathrm{tcPO}_{2}$ during bottle feeding were not observed, and mean $\mathrm{tcPO}_{2}$ levels during bottle feeding (76.1 $\pm 8.5 \mathrm{~mm} \mathrm{Hg}$; mean \pm S.D.) were not significantly different from mean tcPO $\mathrm{O}_{2}$ levels found during states 1,4 , and 5 .

\section{Speculation}

In healthy newborn infants, crying (state 5) may be a physiologic mechanism reducing pulmonary atelectasis acquired during state 2 ("active sleep," "REM sleep").

In the past few years, several reports on continuous monitoring of arterial oxygen tension $\left(\mathrm{PaO}_{2}\right)$ and transcutaneous oxygen tension $\left(\mathrm{tcPO}_{2}\right)$ have demonstrated that in newborn infants with cardiorespiratory disease $(2,5,7,9,17)$ or with severe apnea $(6$, 21,22 ), large fluctuations in $\mathrm{PaO}_{2}$ and in $\mathrm{tcPO}_{2}$ may occur. In contrast, little is known about the fluctuations in $\mathrm{PaO}_{2}$ or in tcPO in healthy, newborn infants (18). Interpretation of the significance of alterations in tcPO $\mathrm{PO}_{2}$ levels in sick infants is difficult without the knowledge of how these levels may vary in normal infants. We therefore recorded tcPO $\mathrm{P}_{2}$ continuously in normal preterm and in normal-term infants. Because many physiologic phenomena change with behavioral state, we assessed this as well. From continuous $\mathrm{tcPO}_{2}$ recordings, a mean $\mathrm{tcPO} \mathrm{P}_{2}$ level was calculated for each behavioral state and used as a basis for comparison. In addition, the effect of bottle feeding on $\mathrm{tcPO}_{2}$ level was also studied.

\section{PATIENTS AND METHODS}

Ten term infants (seven males and three females) and ten preterm infants (six males and four females) without cardiorespiratory disease or severe apnea were studied. Mean birth weight, gestational age, and postnatal age are shown in Table 1. Before each study, informed consent was obtained from the parents. During all studies, infants were clothed in a diaper only. Preterm infants remained in their isolets; term infants were observed in open cots in a heated room. All infants were maintained at their neutral environmental temperature appropriate for their birth weight and postnatal age (13). Term infants were bottle fed at the commencement of the study. Preterm infants were fed by nasogastric drip.

The following parameters were monitored.

\section{TRANSCUTANEOUS $\mathrm{PO}_{2}$}

A Drager $\mathrm{tcPO}_{2}$ electrode heated to $44^{\circ} \mathrm{C}$ was used. The $90 \%$ in vitro response time of the electrode was 10 to $11 \mathrm{sec}$ for a change in $\mathrm{PO}_{2}$ from 155 to $0 \mathrm{~mm} \mathrm{Hg}$. Immediately before and after each study, the electrode was calibrated in vitro using a zero $\mathrm{PO}_{2}$ solution and room air. Studies lasted approximately $3 \mathrm{hr}$. The drift of the electrode was negligible. In all infants, the electrode was placed in the upper right thoracic region, and a "warm-up" time of $30 \mathrm{~min}$ was allowed before commencing the study. The majority of the infants were in state 4 at the beginning of the study. The heat output of the electrode was used as an estimate of skin perfusion (14). $\mathrm{TcPO}$ and heat output of the electrode were continuously recorded.

\section{RESPIRATION}

Respiration was monitored using an impedence pneumogram. A continuous tracing was made throughout the study.

\section{TEMPERATURE}

Body temperature was measured with thermistor probes at two sites (foot sole and rectal) at the beginning and end of the study. Room and incubator temperature were monitored continuously throughout the study.

\section{BEHAVIORAL STATE}

The infants behavioral state was continuously observed and recorded. Assessment was based on the clinical criteria of Prechtl (24). The criteria are:

State 1: eyes closed, no movements, regular respiration;

State 2: cyes closed, no gross movements, irregular respiration;

State 3: eyes open, no gross movements;

State 4: eyes open, gross movements, no crying;

State 5: eyes open or closed, crying.

The respiratory pneumogram was used as an aid in distinguishing states 1 and 2 because regular and irregular breathing patterns could readily be distinguished using the tracing. The study ter- 
Table 1. Details of the infants studied: mean $\pm S . D$. of birth weight, gestational age, and postnatal age

\begin{tabular}{lccc}
\multicolumn{4}{c}{ weight, gestational age, and postnatal age } \\
& $\begin{array}{c}\text { Birth wt } \\
(\mathrm{g})\end{array}$ & $\begin{array}{c}\text { Gestational } \\
\text { age }(\mathrm{wk})\end{array}$ & $\begin{array}{c}\text { Postnatal } \\
\text { age (days) }\end{array}$ \\
\hline Preterm $(n=10)$ & $1505 \pm 154^{1}$ & $32.3 \pm 2.3$ & $8.4 \pm 5.1$ \\
Term $(n=10)$ & $3245 \pm 247$ & $39.9 \pm 0.3$ & $6.3 \pm 3.4$ \\
\hline
\end{tabular}

${ }^{1}$ Mean \pm S.D.

minated when all states had been observed or after $3 \mathrm{hr}$ had elapsed. In addition, $\mathrm{tcPO}_{2}$ before and during bottle feeding in the term infants was also studied and evaluated.

\section{ANALYSIS OF THE DATA}

A typical recording is shown in Figure 1. To compare $\mathrm{tcPO}_{2}$ levels in different states, a mean level was calculated for each state. The mean was calculated from the $\mathrm{tcPO}_{2}$ levels taken at 50 sec intervals during the recording of a particular state. Because state changes are not instantaneous, it was decided not to use that portion of the $\mathrm{tcPO}_{2}$ recording at the beginning of each state epoch in the evaluation. Hence, the first 100 -sec recording of each state epoch was excluded, i.e., if a state was not maintained for at least $100 \mathrm{sec}$, it did not contribute to the data. When an infant's state could not be determined with certainty, that portion of the recording was not used in evaluation.

The total duration of states used for evaluation is shown in Table 2. None of the infants studied was in state 3 for greater than $100 \mathrm{sec}$.

A two-tailed $t$ test was used in the statistical evaluation of the data to compare the mean $\mathrm{tcPO}_{2}$ level in different behavioral states.

\section{PROBLEMS OF THE METHODS}

In this study, we recorded $\mathrm{PO}_{2}$ levels by the transcutaneous method. Several authors have demonstrated that there is a close equivalence between $\mathrm{tcPO}_{2}$ at $44^{\circ} \mathrm{C}$ and $\mathrm{PaO}_{2}$ in neonates $(2,17$, $23,33)$. We therefore did not attempt to further evaluate the relationship between $\mathrm{tcPO}_{2}$ and $\mathrm{PaO}_{2}$ in our infants. Because tcPO $_{2}$ electrodes tend to have a drift, the in vivo calibration of our electrode was carefully checked before and after each study. The drift was negligible. The in vitro response time of our electrode was 10 to 11 sec. This might have caused a lag in the change in $\mathrm{tcPO}_{2}$ level at the time of state changes. This source of error was avoided by excluding the first $100 \mathrm{sec}$ of each state epoch from the evaluation.

Assessment of behavioral state was based on the criteria of Prechtl (24). These state criteria do not include heart rate, eye movements. or electroencephalogram patterns (31). It is possible that assessment of state in our infants would have been aided by the use of an eye movement tracing, but because eye movements can be observed and in addition tend to occur synchronously with observable twitches (26), we also used observable twitches as an aid in determining state 2 . In addition, we recorded the breathing pattern which also allowed us to more readily distinguish states 1 and 2. Behavioral state criteria were originally developed for term infants, and it becomes increasingly difficult to apply them to preterm infants the younger the infants are. This is because cycles of regular and irregular breathing, mobility and quiescence, and rapid eye movement and nonrapid eye movement episodes are seemingly independent of each other until a gestational age of about $36 \mathrm{wk}$ (25). We also observed this in our study. Of the total recording time in preterm infants, $32 \%$ had to be classified as indeterminate compared with only $9 \%$ in term infants.

\section{RESULTS}

Mean $\mathrm{tcPO}_{2}$ and standard deviation for each behavioral state are shown in Table 3 . In one preterm infant, state 1 could not be recorded and in another infant, state 4.
A paired comparison between all states was made. In the preterm infants (Fig. 2), significant differences $(P<0.05)$ were noted between $\mathrm{tcPO}_{2}$ levels in state 2 and states 1,4 , and 5 and also between states 4 and 5 . There was no significant difference between $\mathrm{tcPO}_{2}$ levels in states 1 and 4 and 1 and 5 . With term infants (Fig. 3), significant differences in $\mathrm{tcPO}_{2}$ levels were found between state 2 and states 1,4 , and 5 . Differences were not significant between states 1 and 4,1 and 5 , and 4 and 5 .

$\mathrm{TcPO}_{2}$ levels during bottle feeding (Fig. 4) were similar to those during the awake states 4 and 5 and state 1 and significantly higher than those found in state 2 .

Body temperature of the infants was within the normal range. For the preterm infants, rectal temperature was $37.3 \pm 0.4^{\circ} \mathrm{C}$ (mean \pm S.D.), and foot sole temperature was $35.1 \pm 0.6^{\circ} \mathrm{C}$ (mean

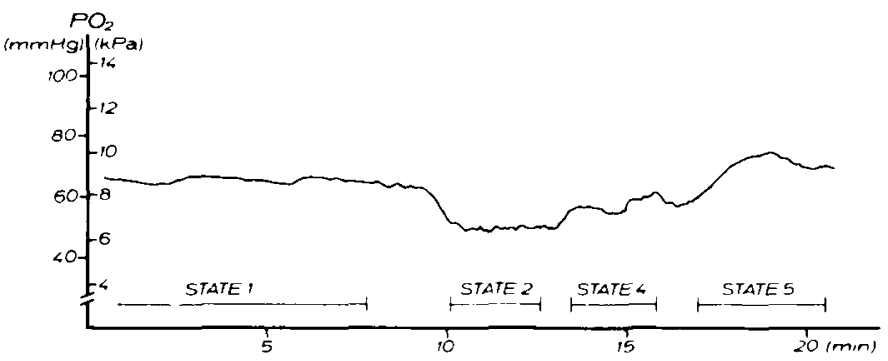

Fig. 1. Continuous $\mathrm{tcPO}_{2}$ tracing of a $3560 \mathrm{~g}$ term infant during the behavioral states $1,2,4$, and 5 . "Stepwise" change in $\mathrm{IcPO}_{2}$ level during state 1 .

Table 2. Total duration of states analysed for transcutaneous $P_{2}$ level excluding the first 100 sec of each state epoch ${ }^{1}$

\begin{tabular}{lcccc}
\hline & $\begin{array}{c}\text { State } 1 \\
(\mathrm{~min})\end{array}$ & $\begin{array}{c}\text { State } 2 \\
(\mathrm{~min})\end{array}$ & $\begin{array}{c}\text { State 4 } \\
(\mathrm{min})\end{array}$ & $\begin{array}{c}\text { State 5 } \\
(\mathrm{min})\end{array}$ \\
\hline Preterm $(n=10)$ & 142 & 352 & 73 & 68 \\
Term $(n=10)$ & 185 & 279 & 98 & 63 \\
\hline
\end{tabular}

${ }^{1}$ No epochs of state 3 longer than $100 \mathrm{sec}$ were observed.

Table 3. Transcutaneous $P O .2$ levels, mean $\pm S . D$., in different behavioral states

\begin{tabular}{ccccc}
\hline Infant & $\begin{array}{c}\text { State 1 } \\
(\mathrm{mm} \mathrm{Hg})\end{array}$ & $\begin{array}{c}\text { State } 2 \\
(\mathrm{~mm} \mathrm{Hg})\end{array}$ & $\begin{array}{c}\text { State 4 } \\
(\mathrm{mm} \mathrm{Hg})\end{array}$ & $\begin{array}{c}\text { State 5 } \\
(\mathrm{mm} \mathrm{Hg})\end{array}$ \\
\hline $\begin{array}{c}\text { Preterm infants } \\
\text { I }\end{array}$ & $58.1 \pm 2.9^{1}$ & $49.4 \pm 3.7$ & $58.5 \pm 2.2$ & $60.7 \pm 1.1$ \\
2 & $85.6 \pm 2.0$ & $84.4 \pm 3.0$ & $87.6 \pm 2.6$ & $91.0 \pm 3.0$ \\
3 & $70.5 \pm 3.8$ & $61.3 \pm 2.8$ & & $69.0 \pm 7.1$ \\
4 & $48.0 \pm 0.0$ & $48.9 \pm 1.3$ & $50.7 \pm 1.2$ & $54.0 \pm 2.0$ \\
5 & $99.1 \pm 2.0$ & $93.9 \pm 2.9$ & $99.8 \pm 3.0$ & $99.5 \pm 2.5$ \\
6 & $49.7 \pm 0.8$ & $47.1 \pm 3.3$ & $57.0 \pm 6.8$ & $66.0 \pm 4.9$ \\
7 & & $61.6 \pm 3.4$ & $71.1 \pm 4.0$ & $71.0 \pm 1.2$ \\
8 & $74.7 \pm 4.6$ & $66.3 \pm 0.8$ & $67.0 \pm 1.2$ & $72.7 \pm 2.3$ \\
9 & $82.2 \pm 2.3$ & $74.4 \pm 2.4$ & $75.0 \pm 3.5$ & $85.0 \pm 2.0$ \\
10 & $45.6 \pm 2.6$ & $42.0 \pm 1.3$ & $62.2 \pm 5.0$ & $59.5 \pm 2.1$
\end{tabular}

Term infants

\begin{tabular}{ccccc}
1 & $63.3 \pm 2.0$ & $54.5 \pm 3.6$ & $86.8 \pm 5.0$ & $81.0 \pm 6.4$ \\
2 & $82.9 \pm 4.1$ & $76.1 \pm 1.5$ & $78.3 \pm 3.4$ & $72.9 \pm 5.4$ \\
3 & $81.4 \pm 2.8$ & $70.4 \pm 1.6$ & $76.8 \pm 1.6$ & $81.6 \pm 0.9$ \\
4 & $70.9 \pm 1.0$ & $72.1 \pm 1.1$ & $74.7 \pm 1.6$ & $74.5 \pm 2.3$ \\
5 & $65.5 \pm 1.7$ & $57.4 \pm 2.7$ & $63.8 \pm 4.6$ & $60.7 \pm 3.7$ \\
6 & $82.8 \pm 2.0$ & $79.6 \pm 4.8$ & $83.2 \pm 5.2$ & $78.0 \pm 0.0$ \\
7 & $62.1 \pm 2.0$ & $55.3 \pm 4.1$ & $66.2 \pm 7.1$ & $59.2 \pm 7.1$ \\
8 & $63.7 \pm 1.6$ & $59.8 \pm 3.1$ & $67.3 \pm 3.7$ & $50.7 \pm 3.5$ \\
9 & $69.1 \pm 5.7$ & $65.7 \pm 4.5$ & $70.4 \pm 3.0$ & $72.0 \pm 3.7$ \\
10 & $60.2 \pm 2.4$ & $53.6 \pm 4.5$ & $58.1 \pm 5.3$ & $59.0 \pm 3.5$ \\
\hline
\end{tabular}

${ }^{1}$ Mean \pm S.D 
\pm S.D.). For term infants, rectal temperature was $37.4 \pm 0.3^{\circ} \mathrm{C}$ (mean \pm S.D.), and foot sole temperature was $35.5 \pm 0.5^{\circ} \mathrm{C}$ (mean \pm S.D.).

The heat output measurements of the electrode did not show any consistent variation with behavioral state.

\section{DISCUSSION}

The results of our study demonstrate that $t c \mathrm{PO}_{2}$ levels in normal term and preterm infants are affected by behavioral state. In most of the infants studied, $\mathrm{tcPO}_{2}$ levels were lowest during the sleep state 2 and significantly higher in the sleep state $I$ and in the awake states 4 and 5 .

Research on the subject of behavioral states by other workers has shown that the cardiorespiratory changes occurring in the different states are diverse. Heart rate is 4.4 to $6 \%$ (mean) greater in state 2 than during state $1(11,15)$. Similarly respiration rate and minute ventilation are increased during state $2(1,8,15)$. Oxygen consumption is also 4.8 to $9.4 \%$ (mean) greater during

PRETERM INFANTS

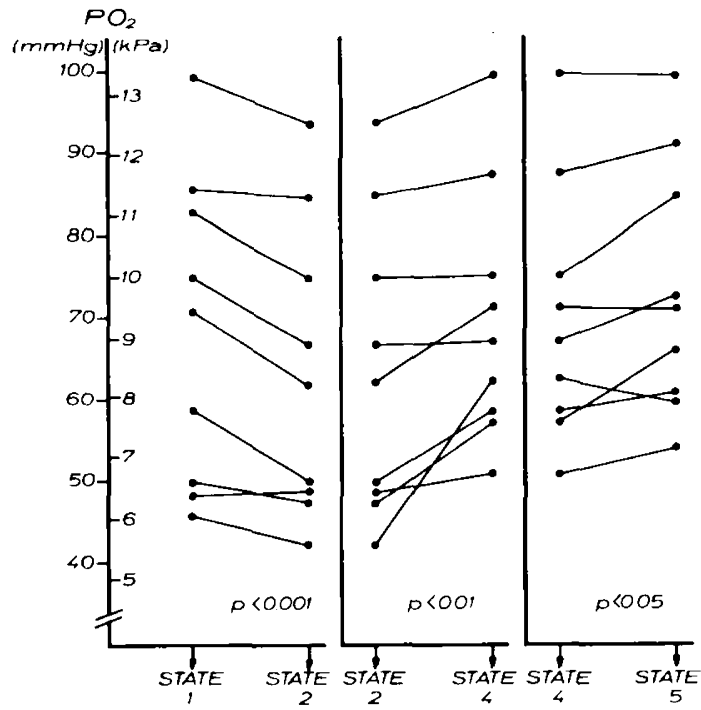

Fig. 2. Preterm infants: comparison of mean $\mathrm{tcPO}_{2}$ levels between states 1 and 2, states 2 and 4 , and states 4 and state 5 .

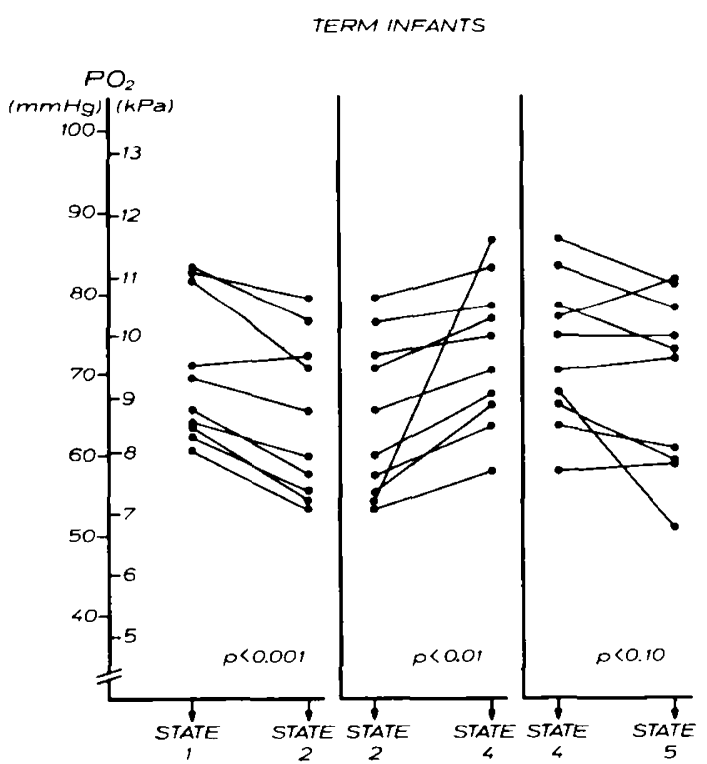

Fig. 3. Term infants: comparison of mean tcPO $\mathrm{PO}_{2}$ levels between states 1 and 2 , states 2 and 4 , and states 4 and state 5 .
TERM INFANTS

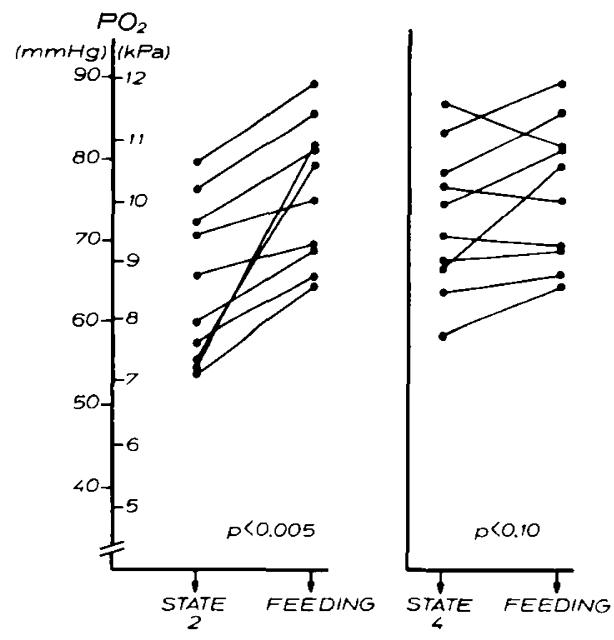

Fig. 4. Term infants: comparison of mean $\mathrm{tcPO}_{2}$ levels during bottle feeding with levels during states 2 and 4.

state 2 when compared with state $1(15,32)$, and there is a further increase in oxygen consumption in the awake states $(17,30)$. In contrast, a decrease in synchronous rib cage movements (18) and a mean $8.4 \%$ decrease in $\mathrm{tcPO}_{2}$ in term infants has been observed in state 2 (18) as well as a mean $31 \%$ decrease in thoracic gas volume (12). In our study, we observed a mean $7.9 \%$ decrease in $\mathrm{tcPO}_{2}$ in the preterm infant group and a mean $8.3 \%$ decrease in $\mathrm{tcPO}_{2}$ in the term infant group in state 2 when compared to state 1. In both infant groups, there was an increase in $\mathrm{tcPO}_{2}$ in the awake states 4 and 5 to levels similar to those of state 1 . Our data demonstrate that in normal infants $\mathrm{tcPO}_{2}$ is maintained at a constant level throughout the different behavioral states except for state 2.

A few authors have tried to explain the fall in $\mathrm{tcPO}_{2}$ occurring in the sleep state 2. Kairam et al. (15) suggested that the transition from NREM (state 1) to REM sleep (state 2) is accomplished by widespread alterations in autonomic functions, which could reflect instability and/or vulnerability of control mechanisms during this period. Martin et al. (18) suggested that as a result of motor neuron inhibition during "active sleep" (state 2) (10) accompanied with asynchronous rib cage movements, local areas of atelectasis might develop leading to a decrease in ventilation/perfusion ratios. Increased oxygen consumption in state 2 might be a factor contributing to the fall in $\mathrm{tcPO}_{2}$ if there is a greater venous admixture within the lung. Assuming that in our infants oxygen consumption and minute ventilation also were increased in state 2 with a further increase in states 4 and 5 , this did not affect tcPO levels in states 4 and 5 . In spite of cardiorespiratory changes in the different states, the infants were able to maintain $\mathrm{tcPO}_{2}$ at a constant level throughout states 1,4 , and 5 except for state 2 . Although it seems likely that the fall in $\mathrm{tcPO}_{2}$ in state 2 is the result of an increased ventilation/perfusion imbalance, our data indicate that a limited response to arterial oxygen tension in regulation of breathing in state 2 cannot be excluded.

It is possible that the order in which behavioral states occur may have affected $\mathrm{tcPO}_{2}$ levels. Stothers and Warner (32) demonstrated that in term newborn infants oxygen consumption rates differ depending on the order of the states, a significant difference being observed when the infants direction of sleep state change was from "Non REM sleep" (state 1) to "REM sleep" (state 2). No significant difference in oxygen consumption was observed when REM sleep (state 2) preceeded non-REM sleep (state 1). In our infants, sleep states occurred mainly in the order state 2 to state 1 , this probably being influenced by feeding the infants at the beginning of the study. Hence, we observed a significant increase in $\mathrm{tcPO}_{2}$ level when the direction of sleep state change was from state 2 to state 1 . 
Visual analysis of $\mathrm{tcPO}_{2}$ tracings during state 1 showed two distinct patterns. In one pattern, the $\mathrm{tcPO}_{2}$ level remained constant throughout the epoch, and in the other pattern, the $\mathrm{tcPO}_{2}$ level increased and decreased in a stepwise fashion. It was noted that each "step" in this second pattern was immediately preceeded by a startle and a very short apnea. The time interval between steps was 1 to $4 \mathrm{~min}$ (Fig. 1).

Polygraphic studies on newborn infants have shown that the tonic activity of muscle groups in the body during state 1 increases and decreases in a stepwise fashion (29). Changes in tonic activity are preceeded by a startle (25). The alternations in tone occur periodically and with a preferred time interval of $3 \mathrm{~min}$ (29). It would seem that the characteristic stepwise changes in $\mathrm{tcPO}_{2}$ level and tonic activity are in some way related and possibly reflect alterations in muscle tone.

Other than in state $1, \mathrm{tcPO}_{2}$ tracings did not appear to conform to any pattern except a group of four recordings in preterm infants in state 2 who had periodic breathing. This was associated with a sine wave-like pattern on the $\mathrm{tcPO}_{2}$ tracing with changes of $\mathrm{tcPO}_{2}$ level of 4 to $5 \mathrm{~mm} \mathrm{Hg}$ with each cycle (Fig. 5). Analysis of the pneumogram and $\mathrm{tcPO}_{2}$ recording showed that they both had the same frequency.

When $\mathrm{tcPO}_{2}$ levels during states 4 and 5 are compared. Levels were significantly higher $(P<0.05)$ in state 5 in the preterm infant group; there was no significant change in the term infant group. In all preterm infants, crying resulted in an increase in $\mathrm{tcPO}_{2}$. Of the term infants, four had an increase in $\mathrm{tcPO}_{2}$, and six had a decrease in $\mathrm{tcPO}_{2}$ during crying. Apparently, circulatory and respiratory changes that occur during crying $(3,5,16)$ may result in either an increase or a decrease in $\mathrm{tcPO}_{2}$. The mechanisms responsible for the direction of the change in $\mathrm{tcPO}_{2}$ during crying are not yet fully understood (5). Presumably, crying affects ventilation/perfusion ratios as changes in intrathoracal pressure from -18.8 to $+40 \mathrm{~cm} \mathrm{H}_{2} \mathrm{O}$ or more in crying newborn infants have been measured $(5,16)$. It is therefore possible that in the infants with an increase in $\mathrm{tcPO}_{2}$ during crying, local areas of atelectasis have been reduced leading to increased ventilation/perfusion ratios. From this point of view, crying may be an important physiologic mechanism compensating for atelectasis that may have developed during state 2 . Assuming that in the infants with a decrease in $\mathrm{tcPO}_{2}$ during crying ventilatory changes were similar to those in the other infants, the fall in $\mathrm{tcPO}_{2}$ can only be explained by circulatory changes resulting in an increased right-to-left shunt. In these infants, increased pulmonary vascular resistance and right-to-left shunting during crying may play a role. Pulmonary vascular resistance drops markedly immediately after birth with a further gradual decrease in the first wk of life $(27,28)$. There are, however, marked individual differences (27), and pulmonary vascular resistance may have been increased in some of our infants. Our finding that there is no fall in $\mathrm{tcPO}_{2}$ levels in the majority of our infants when active, crying, or bottle feeding is contrary to the observation in sick infants, where restlessness or crying usually results in a fall in $\mathrm{tcPO}_{2}$ level $(4,20)$. It is evident

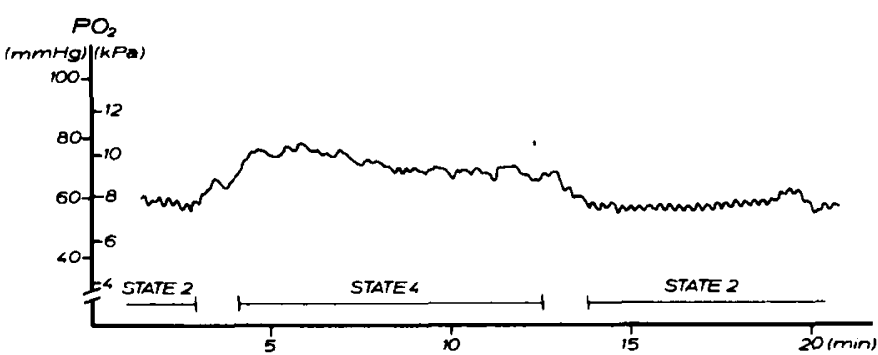

Fig. 5. Continuous $\mathrm{tcPO}_{2}$ tracing of a $1580 \mathrm{~g}$ premature infant. During state 2 , this infant had periodic breathing and shows a sine wave-like pattern on the $\mathrm{tcPO}_{2}$ tracing. now that the response of sick infants to these situations is different to that of normal infants (5). Measuring $\mathrm{tcPO}_{2}$ levels during activity and crying may be of particular clinical value in monitoring infants with cardiorespiratory disease.

\section{REFERENCES AND NOTES}

1. Bolton, D. P., and Herman, S.: Ventilation and sleep state in the newborn. J. Physiol. (Lond.), 240: 67 (1974).

2. Boyle, R. L., and Oh, W.: Transcutaneous $\mathrm{PO}_{2}$ monitoring in infants with persistent fetal circulation who are receiving tolazoline therapy. Pediatrics, 62: 605 (1978).

3. Buda, A. J., Pinsky, M. R., Ingels, N. B., Daughters, G. T., Stinson, E. B., and Alderman, E. L.: Effect of intrathoracic pressure on left ventricular performance. N. Engl. J. Med., 301: 452 (1979).

4. Dangman, B. C., Hegyi, T., Hiatt, M., Indyk, L., and James, L. S.: The variability of $\mathrm{PO}_{2}$ in normal infants in response to routine care. Pediatr. Res. (Abstract), 10: 422 (1976).

5. Dinwiddie, R., Pitcher-Wilmott, R., Schwartz, J. G., Shaffer, T. H., and Fox, W. W.: Cardiopulmonary changes in the crying neonate. Pediatr. Res., 13: 900 (1979).

6. Ekert, W. D., Apitz, J., König, C., and Schenck, H. W.: Apnoen, Herzfrequenzänderungen und transcutane $\mathrm{PO}_{2}$ Anderung bei atemgestörten Früh- and Neugeborenen. Mschr. Kinderheilk., 125: 425 (1977).

7. Fenner, A., Müller, R., Busse, H. G., Junge, M., and Wolsdorf, J.: Transcutaneous determination of arterial oxygen tension. Pediatrics, 55: 244 (1975).

8. Finer, N. N., Abroms, I. F., and Taeusch, H. W.: Ventilation and sleep states in newborn infants. J. Pediatr., 89: 100 (1976)

9. Fox, W. W., Schwartz. J. G., and Schaffer, T. H.: Pulmonary physiotherapy in neonates: physiologic changes and respiratory management. J. Pediatr., 92: 977 (1978).

10. Gabriel, M., Albani, M., and Schulte, F. J.: Apneic spells and sleep states in preterm infants. Pediatrics, 57: 142 (1976).

11. Harper, R. M., Hoppenbrouwers, T., Sterman, M. B., McGinty, D. J., and Hodgman, J.: Polygraphic studies of normal infants during the first six months of life. 1. Heart rate and variability as a function of state. Pediatr. Res., 10:945 (1976).

12. Henderson-Smart, D. J., and Read, D. J.: Depression of intercostal and abdominal muscle activity and vulnerability to asphyxia during active sleep in the newborn. In: C. Guilleminault, W. Dement: Sleep and Apnea Syndromes: (Alan R. Liss, New York, 1978).

13. Hey, E. N., and Katz, G.: The optimum thermal environment for naked babies. Arch. Dis. Child., 45: 328 (1970).

14. Huch, R., Huch, A., Albani, M., Gabriel, M., Schulte, F. J., Wolf, H., Rupprath, G., Emmrich, P., Stechele, U., Duc, M. D., and Bucher, H.: Transcutaneous $\mathrm{PO}_{2}$ monitoring in routine management of children with cardio-respiratory problems. Pediatrics, 57: 681 (1976).

15. Kairam, R., Schulze, K., Koeningsberger, M., and James, L. S.: The effects of changing sleep states on autonomic functions in the newborn. Pediatr. Res. (Abstract), 13: 498 (1979).

16. Kraus, A. N., Klain, D. B., Dahms, B. B., and Auld, P. A. M.: Vital capacity in premature infants. Am. Rev. Respir. Dis., 108: 1361 (1973)

17. le Souëf, P. N., Morgan, A. K., Soutter, L. P., Reynolds, E. O. R., and Parker, D.: Comparison of transcutaneous oxygen tension with arterial oxygen tension in newborn infants with severe respiratory illness. Pediatrics, 62: 692 (1978).

18. Martin, R. J., Okken, A., and Rubin, D.: Arterial oxygen tension during active and quiet sleep in the normal neonate. J. Pediatr., 94: 271 (1979).

19. Mestyán, J., Jarai, I., and Fekete, M.: The total energy expenditure and its components in premature infants maintained under different nursing and environmental conditions. Pediatr. Res. 2: 161 (1968).

20. Okken, A., Rubin, I. L., and Martin, R. J.: Intermittent bag ventilation of preterm infants on positive airway pressure. J. Pediatr., 93: 279 (1978).

21. Peabody, J. L., Gregory, G. A., Willis, M. M., and Tooley, W. H.: The Huch transcutaneous $\mathrm{PO}_{2}$ electrode in sick infants. Pediatr. Res. (Abstract), 10: 430 (1976).

22. Peabody, J. L., Neese, A. L., Philip, A. G. S., Lucey, J. F., and Soyka, L. F.: Transcutaneous oxygen monitoring in aminophylline-treated apneic infants. Pediatrics, 62: 698 (1978).

23. Pollitzer, M. J., Morgan, A. K., Reynold, E. D. R., and Soutter, L. P.: Continuous comparison of in vitro and in vivo-calibrated transcutaneous oxygen tension $\left(\mathrm{tcPO} \mathrm{O}_{2}\right)$ with arterial oxygen tension $\left(\mathrm{P}_{2} \mathrm{O}_{2}\right)$ in infants with respiratory illnesses. Pediatr. Res., 13: 81 (1979).

24. Prechtl, H. F. R.: The behavioural states of the newborn infant (a review). Brain Res., 76: 185 (1974)

25. Prechtl, H. F. R., Fargel, J. W., Weinmann, H. M., and Bakker, H. H.: Postures, mobility and respiration in low-risk preterm infants. Dev. Med. Child Neurol., 21: 3 (1979).

26. Prechtl, H. F. R., and Lenard, H. G.: A study of eye movements in sleeping newborn infants. Brain Res., 5: 477 (1967)

27. Riggs, T., Hirschfeld, S., Bormuth, C., Fanaroff, A., and Liebman, J.: Neonatal circulatory changes: an echocardiographic study. Pediatrics, 59: 338 (1977).

28. Rudolph, A. M.: The changes in the circulation after birth: their importance in congenital heart disease. Circulation, 41: 343 (1970).

29. Schloon, H., O'Brien, M. J., Scholten, C. A., and Prechtl, H. F. R.: Muscle activity and postnatal behaviour in newborn infants. Neuropaediatrie, 7: 384 (1976). 
30. Scopes, J. W., and Iqbal, A.: Minimal rates of oxygen consumption in sick and premature newborn infants. Arch. Dis. Child., 41 : 407 (1966).

31. Shirataki, S., and Prechtl, H. F. R.: Sleep state transitions in newborn infants: a preliminary study. Dev. Med. Child. Neurol., 19: 316 (1977).

32. Stothers, J. K., and Warner, R. M.: Oxygen consumption and neonatal sleep states. J. Physiol. (Lond.), 278: 435 (1978).

33. Versmold, H. T., Holzmann, M., Linderkamp, O., and Riegel, K. P.: Skin oxygen permeability in premature infants. Pediatrics, 62: 488 (1978).
34. The authors wish to thank Prof. Heinz Prechtl and Dr. John O'Brien for their excellent advice and Erik van Binsbergen for his technical assistance.

35. Requests for reprints should be addressed to: Dr. A. Okken, Department of Pediatrics, Division of Neonatalogy, University Hospital, 59 Oostersingel, 9700 RB Groningen, The Netherlands.

36. Received for publication April 2, 1979.

37. Accepted for publication November 6, 1979. 